Historic, Archive Document

Do not assume content reflects current scientific knowledge, policies, or practices. 



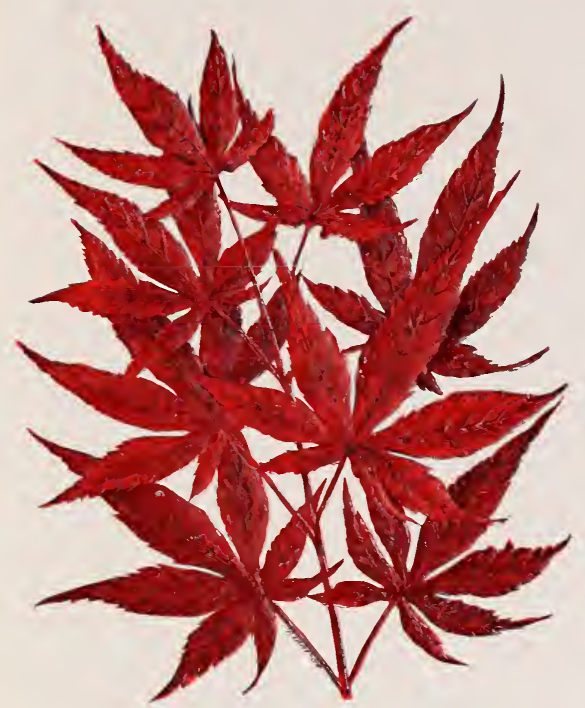

\section{The Japanese Blood-Leaved Maple}

FEW plants have given such widespread satisfaction or have been so largely planted as this charming JAPANESE MAPLE. Its adaptability to so many situations in planting arrangements, its blood red foliage making a striking contrast with its surroundings, and its compact, regular growth, makes it the most useful of ornamental plants.

It can be used as a single specimen, in groups of three or more, or in beds of large growing shrubs. As a single specimen on small lawns it has no equal.

PRICES:

18 to 24 inch plants, $\$ 1.00$ each; $\$ 7.50$ per to. 2 to $21 / 2$ feet, $\$ 1.50$ each; $\$ 12.50$ per 10. 3 feet specimens, $\$ 2.00$ to $\$ 3.00$ each.

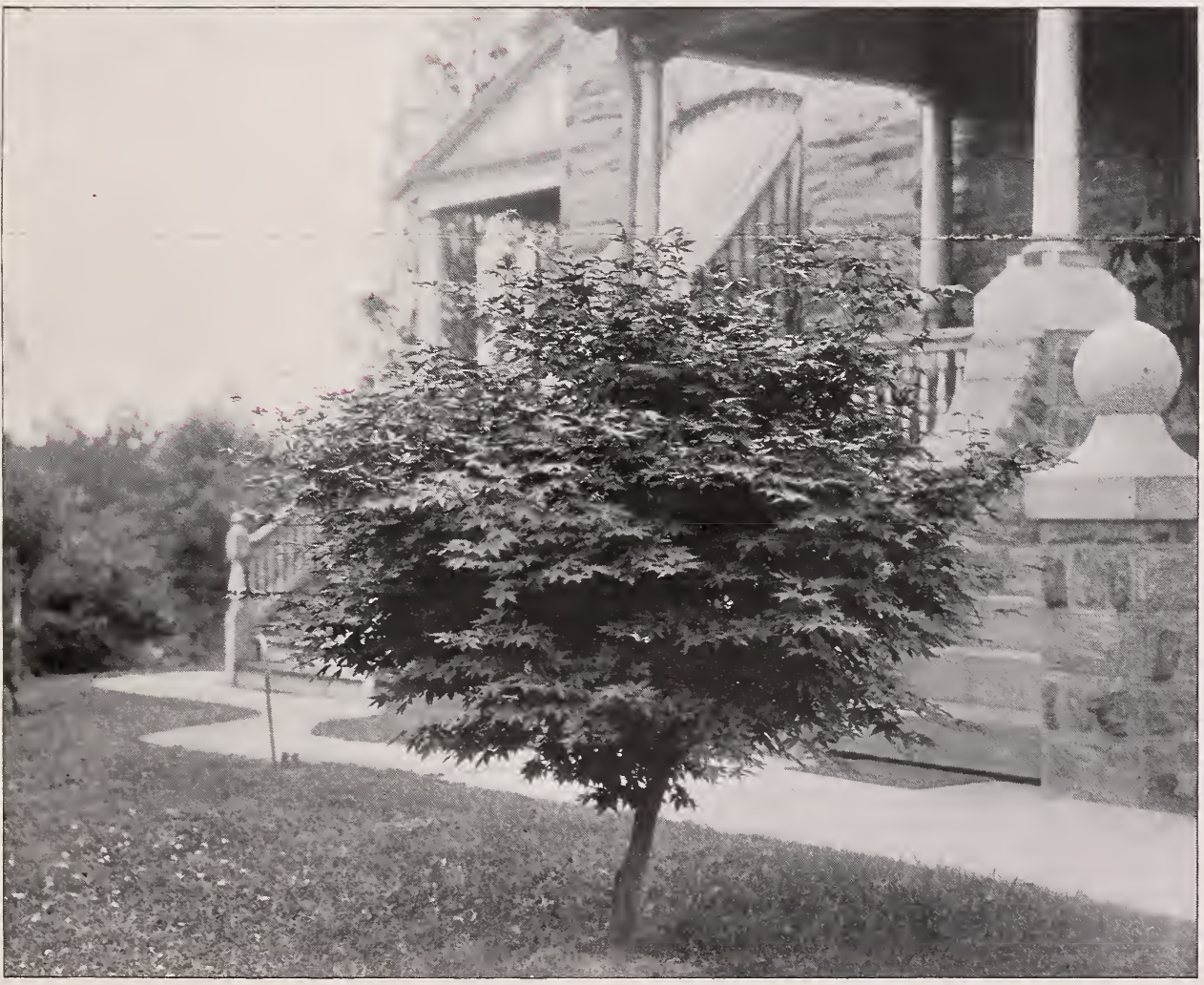


<smiles>CCC(C)(CC)C(CC)(CC)C(C)(C)C</smiles> 